\title{
THE "FUNDAMENTAL TRANSFORMATION" IN MACROECONOMICS
}

\author{
Ricardo J. Caballero \\ Mohamad L. Hammour
}

Working Paper 5471

\section{NATIONAL BUREAU OF ECONOMIC RESEARCH 1050 Massachusetts Avenue Cambridge, MA 02138 \\ February 1996}

We thank Olivier Blanchard and Steven Davis for helpful comments. This paper was prepared for the AER Papers and Proceedings of the AEA Meetings held in San Francisco, January 5-7, 1996. This paper is part of NBER's research program in Economic Fluctuations and Growth. Any opinions expressed are those of the authors and not those of the National Bureau of Economic Research.

(C) 1996 by Ricardo J. Caballero and Mohamad L. Hammour. All rights reserved. Short sections of text, not to exceed two paragraphs, may be quoted without explicit permission provided that full credit, including () notice, is given to the source. 


\title{
THE "FUNDAMENTAL TRANSFORMATION" \\ IN MACROECONOMICS
}

\begin{abstract}
When factors enter into joint-production, they typically develop a degree of specificity with respect to each other. It is well known that, when combined with contracting difficulties, specificity gives rise to a Williamsonian "Fundamental Transformation" from an ex-ante competitive relationship to an ex-post bilateral monopoly. The macroeconomic consequences of widespread specificity are far-reaching. Specificity results in misallocation, underutilization, and unemployment of the economy's productive factors; it hampers growth by depressing the incentives to replace what is outdated and to fully utilize the economy's resources; it disrupts macroeconomic adjustment by inducing a wedge between timid creation and excessive destruction of the old system; and it exacerbates downturns by "elastifying" the cyclical response of inelastic factors.
\end{abstract}

Ricardo J. Caballero

Department of Economics

Massachusetts Institute of Technology

50 Memorial Drive

Cambridge, MA 02139

and NBER
Mohamad L. Hammour

Capital Guidance

32 avenue Hoche

75008 Paris

FRANCE 


\title{
The "Fundamental Transformation" in Macroeconomics
}

\author{
By Ricardo J. Caballero and Mohamad L. Hammour ${ }^{1}$
}

When factors enter into joint production, they often develop a degree of "specificity" with respect to each other. Their value in the context where they have come to produce exceeds their outside value. Committing a production factor in such a relationship is a form of specific investment, whose sunk component may have technological as well as institutional origins.

By itself, this "irreversibility" has important and extensively studied implications for investment decisions. But, when combined with contracting problems, it acquires an entirely new dimension. When two factors enter into a joint-production relationship, specificity creates ex-post quasi-rents that need to be protected through ex-ante contracting. Unless complete and enforceable contracts are available, those quasi-rents may be appropriated by the other factor. This transformation from an ex-ante competitive setting to an ex-post bilateral monopoly - what Oliver Williamson terms the "Fundamental Transformation" — is a central building block in the modern economic theory of institutions (e.g., Benjamin Klein, Robert Crawford, and Armen Alchian, 1978; Williamson, 1979).

The problem of appropriability spreads unprotected quasi-rents throughout the economy, and leads to under-investment in partial equilibrium. In general equilibrium, the market system will adjust to help partly compensate the appropriated factors, providing a highly inefficient macroeconomic "solution" to the unresolved microeconomic contracting problems. Appropriability affects major aspects of the macroeconomy. It results in misallocation, underutilization, and unemployment of the economy's productive factors; It hampers growth by depressing the incentives to replace what is outdated and to fully utilize the economy's resources; It disrupts macroeconomic adjustment, by inducing a wedge

\footnotetext{
${ }^{1}$ Caballero: Department of Economics, Massachusetts Institute of Technology, 50 Memorial Drive, Cambridge, MA 02139 and NBER; Hammour: Capital Guidance, 32 avenue Hoche, 75008 Paris, France. We thank Olivier Blanchard and Steven Davis for helpful comments. This paper was prepared for the AER Papers and Proceedings of the AEA Meetings held in San Francisco, January 5-7, 1996.
} 
between timid creation and excessive destruction of the old system; And it exacerbates downturns by "elastifying" the cyclical response of inelastic factors.

\section{Microeconomics}

The prototypical macroeconomic example of specificity we choose to focus on is that of the relationship between capital and labor. Other examples are also important, and affect such diverse relations as that between an entrepreneur and his external sources of finance (see, e.g., Ricardo Caballero and Mohamad Hammour, 1996c), or that between an upstream firm and its downstream customers (as discussed extensively in the microeconomic literature on vertical integration).

In the presence of specificity, the central unit of analysis is the joint-production relation between the factors. We embody this relation in the concept of a "production unit" which, we assume, combines in fixed proportions one unit of capital and one unit of labor. Because of specificity, production units cannot be costlessly reshuffled. It is therefore meaningful to analyze both the creation decision, by which factors choose to enter into a production relation, and the destruction decision, by which factors within an existing production unit choose whether to continue producing jointly or not.

We outline a minimalist model to help structure our discussion. For a more complete treatment, we refer the reader to Caballero and Hammour (1996a, b, c, d). The units of analysis that arise from the notion of specificity provide the natural setting for a Schumpeterian view of a macroeconomy with ongoing creation and destruction (see, e.g., Caballero and Hammour, 1994). In this short paper, however, we reduce our treatment of dynamics to a minimum. We model destruction and creation decisions during a single period. We assume that factors can either be part of a production unit in the Joint-Production sector, or remain in their Autarchy sectors. The period starts with pre-existing production units as well as a supply of uncommitted units of capital and labor. First, the factors in all preexiting units decide whether to produce jointly in the coming period, or to separate and join the uncommitted factors; Second, all uncommitted factors either form new production 
units or remain in Autarchy; Finally, production of the economy's unique consumption good takes place in the Joint-Production and Autarchy sectors.

Creation. Let us denote by $y$ the production revenue of a newly created production unit, and by $w_{k}$ and $w_{l}$ the revenue of capital and labor in Autarchy (all in terms of the consumption good). In partial equilibrium, the efficient decision is to create a production unit as long as

$$
y \geq w_{k}+w_{l}
$$

This rule would, in fact, be followed as long as factors of production can freely and costlessly move in and out of production units.

Specificity. Such freedom of movement rarely holds in reality. Let us take the extreme irreversible-investment view, where once locked into a specific relationship, capital is lost if the relationship breaks up. Although it can also be due to such institutional factors as organized labor or legislated firing costs, we view specificity here as a purely technological phenomenon. As a result, while the ex-ante opportunity cost of capital is $w_{k}$, its ex-post opportunity cost is zero. On the other extreme, we assume labor develops no specificity with respect to the relationship, so $w_{l}$ represents both its ex-ante and its ex-post opportunity cost.

The Fundamental Transformation. If capital and labor were able to precommit to their ex-post terms of trade, they would follow the efficient entry rule. But when complete contracts are costly to write and enforce, agents' ability to precommit is limited and a Williamsonian "Fundamental Transformation" arises: the ex-ante competitive relationship between capital and labor turns into an ex-post bilateral monopoly. Assuming no precommitment is possible, the specific quasi-rent $s$ from a production unit is the difference between the unit's revenue and its factors' ex-post opportunity costs:

$$
s \equiv y-w_{l}
$$


Following the Nash bargaining solution for sharing the unit's revenue, we assume each factor gets its ex-post opportunity cost plus half of the unit's bargaining-surplus $s$. Using the superscript $j$ to denote payments to factors in new Joint-Production units, we have

$$
\begin{gathered}
w_{k}^{j}=\frac{s}{2} . \\
w_{l}^{j}=w_{l}+\frac{s}{2},
\end{gathered}
$$

Under-investment. It is clear from equations (3) and (4) that labor will willingly participate in production as long as the surplus from joint production is non-negative. Capital, the factor that is vulnerable to appropriation, requires more. Its share of the ex-post surplus must be enough to justify forfeiting its ex-ante opportunity cost:

$$
\frac{s}{2} \geq w_{k}
$$

Replacing (2) into this expression yields the entry condition more explicitly

$$
y \geq 2 w_{k}+w_{l}
$$

which states that a unit's revenue must not only cover its factors' opportunity costs, as in the efficient condition (1), but must also generate enough rents for capital to recover its ex-ante opportunity cost after being appropriated. This increased-revenue requirement generally gives rise to an under-investment problem, a result most clearly stated by Paul Grout (1984) in this context.

Destruction. The other decision of interest to us is that of a pre-existing production unit with production revenue $x$ that must decide whether to remain in operation or shut down and free its non-specific resources. The privately efficient rule is to exit if the opportunity cost of the two factors of production cannot be covered. Since capital is fully specific, its opportunity cost is zero. On the other hand, the opportunity cost of labor in a pre-existing 
unit is $p w_{l}^{j}+(1-p) w_{l}$, where $p$ is the probability of finding employment in Joint Production (see below). The exit rule is therefore

$$
x<p w_{l}^{j}+(1-p) w_{l}
$$

In the context of bilateral bargaining, the question of the private efficiency of separations arises. When there is a "non-transferability" problem, due, for example, to asymmetric information (as in Robert Hall and Edward Lazear, 1984, e.g.) or to a minimum-wage constraint, the exit decision may be privately inefficient (see, e.g., Roger Myerson and Mark Satterthwaite, 1983). We abstract away from this possibility, and assume for simplicity that exit decisions are privately efficient. This is in sharp contrast, as we will see, with their social inefficiency at the macroeconomic level.

\section{MACROECONOMICS}

In our simple setup, macroeconomic analysis consists of understanding the equilibrium determination of factor rewards in Autarchy and Joint Production, and the corresponding utilization of the economy's factor endowments. For this, we assume that the initial aggregate supply of uncommitted factors is one for both capital and labor. To simplify the determination of equilibrium quantities, we also assume that pre-existing production units are of infinitesimal mass. We assume that, in its Autarchy sector, capital can be turned one-to-one into the consumption good, so $w_{k}=1$. On the other hand, labor experiences decreasing returns in its Autarchy sector, resulting in a Joint-Production labor supply function

$$
w_{l}=2 L^{1 / \eta}, \quad \eta>0
$$

where $L$ measures Joint-Production employment. The supply of capital into Joint Production is therefore perfectly elastic, while the supply of labor is partly inelastic. Finally, we restrict our analysis to values of $y \in(2,3)$, where both the efficient and inefficient economies exhibit positive but not full employment in Joint Production. 


\section{A. The Efficient Economy}

If precommitment with complete and enforceable contracts is available, equilibrium will be efficient. Capital and labor will receive their ex-ante equilibrium opportunity cost in Joint Production. An interior solution in this case requires that entry condition (1) hold with equality. Denoting efficient levels by a star, and recalling that $w_{k}^{*}=1$, the opportunity cost of labor is

$$
w_{l}^{*}=y-1
$$

Taking labor supply (7) into account, the efficient Joint-Production level of employment is

$$
L^{*}=\left[\frac{y-1}{2}\right]^{\eta}
$$

Finally, since labor receives its ex-ante opportunity cost in Joint Production (i.e. $w_{l}^{j *}=w_{l}^{*}$ ), exit rule (6) in the efficient economy is simply

$$
x<w_{l}^{*}
$$

\section{B. Incomplete-Contracts Equilibrium}

We now characterize equilibrium for an economy with no contractual precommitments, and compare it with the efficient economy.

Depressed creation. In general equilibrium, and off corners, entry condition (5) must hold with equality. As before, noting that $w_{k}=1$ and taking labor supply (7) into account, the opportunity cost of labor and the level of Joint-Production employment are equal to

$$
\begin{gathered}
w_{l}=y-2<w_{l}^{*}, \\
L=\left[\frac{y-2}{2}\right]^{\eta}<L^{*} .
\end{gathered}
$$


With incomplete contracts, the "appropriating" factor's opportunity cost and the creation of Joint-Production units are depressed in general equilibrium. In order to ensure a proper return to the "appropriated" factor, the economic system must depress the opportunity cost of labor so that, after all, capital receives its ex-ante required return. This is done by underutilizing labor and, through this mechanism, weakening the bargaining position of "insider" labor.

Market segmentation and unemployment. In equilibrium, the economy must generate a positive Joint-Production surplus $s$ to compensate capital ex post for its ex-ante opportunity cost (see equation (3)). This implies that Joint-Production workers, who share in that surplus, must earn more than those who remain in Autarchy (see equation (4)). The labor market is therefore "segmented" between those two sectors, and workers who remain in Autarchy are, in this sense, involuntarily "unemployed."

In fact, because capital was assumed to be infinitely elastic, the full cost of inefficiency is borne by the unemployed. The Autarchy "wage" $w_{l}$ is depressed in equilibrium so as to reduce the opportunity cost of labor and help compensate capital for appropriation by insider labor. The latter, on the other hand, suffer no welfare loss in the Joint-Production sector, and receive

$$
w_{l}^{j}=w_{l}+\frac{s}{2}=y-1=w_{l}^{*}
$$

Technological Sclerosis. We now turn to the exit decision of a pre-existing production unit with gross revenue $x$. From exit rule (6) in the microeconomics section, we know that the unit will exit if and only if its revenues are lower than $p w_{l}^{j}+(1-p) w_{l}$. It is easy to see that

$$
p w_{l}^{j}+(1-p) w_{l}<w_{l}^{*},
$$

since, by $(10)$ and (12), we know that $w_{l}<w_{l}^{*}$ and $w_{l}^{j}=w_{l}^{*}$, and the probability of finding Joint-Production employment is $p=L<1$. Comparing (6) and (9), this implies that the incomplete-contracts economy keeps low-productivity units in operation that would 
be scrapped in an efficient world. Not only is creation depressed by the appropriability problem, but also pressure on outdated units is reduced by the equilibrium decline of the opportunity cost of labor. This combination makes for a powerful drag on growth.

Scrambling. Efficiently, the scrapping rule is based on a strict productivity-ranking of pre-existing production units - with the least productive units exiting, and others surviving. The ranking that forms the basis for the scrapping rule could be "scrambled" in the presence of appropriability and bargaining inefficiencies. Suppose we had introduced private inefficiency in separations of some form. Some high-productivity units could be destroyed because of private inefficiency, even though they would survive in the efficient economy; Other, much less productive units, if they suffer less from private inefficiency, may survive because of "sclerosis," even though they would be destroyed in the efficient economy. We develop this idea in Caballero and Hammour (1996c) in a model where privately inefficient separations arise because of credit constraints on "continuation investment."

\section{Macroeconomic Response to Shocks}

Specificity together with incomplete contracting not only affects levels, but also the cyclical features of the economy. We now turn to the implications of appropriability for the economy's response to aggregate shocks.

Excessive destruction. Paradoxically, although scrapping is insufficient when compared with the efficient economy, it is excessive given the level of creation. To see this, note that the social shadow wage in this economy is $w_{l}$, while the shadow wage used in the private destruction condition (6) is $p w_{l}^{j}+(1-p) w_{l}>w_{l}\left(\right.$ since $\left.w_{l}^{j}>w_{l}\right)$.

Excessive destruction captures an important aspect of the employment crises that are feared during major macroeconomic adjustment episodes (see Caballero and Hammour, 1996b). The coexistence of sclerosis with excessive destruction also uncovers the fallacious nature, in our context, of the "liquidationist" argument, that sees in a contraction a way to improve welfare by reducing sclerosis. 
Elastification. Consider the economy's response to an aggregate shock to gross revenues $y$. Differentiating the equilibrium employment expressions (8) and (11), one can easily show that

$$
\frac{d L / L}{d y / y}>\frac{d L^{*} / L^{*}}{d y / y}
$$

In other words, the response of the incomplete-contracts economy is more elastic than that of the efficient economy. ${ }^{2}$ A decline in profitability requires a decline in the cost of labor to ensure capital of its required return. This is more difficult to achieve in the presence of appropriable quasi-rents, and requires a proportionally larger decline in employment. More generally, we argue in Caballero and Hammour (1996d) that when the unemployed factor is the less elastic of the two, its cyclical responsiveness will inherit some of the elasticity of the other factor in the presence of appropriability - a phenomenon we term "elastification."

Decoupling. In terms of the joint behavior of creation and destruction flows over the cycle, excessive destruction leads to a "decoupling" of creation and destruction, characterized by a destruction of jobs that is not accompanied by a simultaneous surge in job creation. In Caballero and Hammour (1996a), we argue that this manifestation of inefficiency is broadly consistent with what we know about job flows; In Caballero and Hammour (1996b), we argue for its relevance in accounting for massive employment and output declines during major adjustment episodes.

\section{Policy Considerations}

At a very general level, the multidimensional macroeconomic problem we have described in the previous section stems from ill-defined property rights. These have long been of central concern to development economists - whether they affect the employment relation stressed here, or others, such as external finance. The design of institutions with the ability

\footnotetext{
${ }^{2}$ If $3<A<4$, the elastification result is more stark. The efficient economy exhibits full Joint-Production employment in that case, while the inefficient economy does not. Thus employment does not efficiently respond to aggregate shocks, but does so under incomplete contracts.
} 
to safeguard proper contract enforcement is a main ingredient of a successful development strategy, an old idea that has acquired heightened relevance in the recent Eastern European reform episodes.

But there is no need to go to such extreme episodes. The disruptive consequences of ill-defined property rights are present even in economies with the most developed judicial and regulatory systems. There are aspects of relationships that are simply too difficult to contractually regulate and verify so as to fully protect the investing parties. Under those circumstances, and as a complement to institutional reforms, there is a need to design aggregate policies intended expressly to remedy the macroeconomic consequences of entrenched appropriability problems.

The first and most direct impact of appropriability is under-investment, which calls for some sort of creation incentive. But, in isolation, the benefits of such a policy may come at a significant cost. Because of the wage pressures of increased hiring, a creation incentive may exacerbate the excessive-destruction problem. Thus, excessive destruction calls for another type of policy aimed at protecting existing production units. But, in isolation, such a policy does not address the need for more creation incentives and, depending on the form it takes, may actually further depress creation.

The problem of these two approaches, considered in isolation, is that while partially correcting the distortion along one margin, they fail to address - and often exacerbate - the distortion on the other. To address this problem, one must not only raise the level of creation, but also succeed in "synchronizing" destruction with it. Only a well-balanced combination of creation incentives and protection of the existing structure can succeed in achieving those goals. In fact, it is straightforward to show in our simple model that both problems are solved by simultaneously implementing an investment subsidy equal to $w_{k}$, and a job-protection subsidy $L^{*} s^{*} / 2$ to pre-existing units if they remain in operation.

This two-pronged approach offers a useful framework to discuss macroeconomic policy in a variety contexts. On adjustment strategies, it highlights the limitations of the "gradualism versus cold-turkey" debate, which, in its purest form, is a debate confined within the set 
of single-instrument policies aimed at slowing destruction. In Caballero and Hammour (1996b), we argue that Korea provides a good example of the managed-adjustment policies that stem from our framework, where investment incentives through the credit market were complemented with protection of domestic sectors, as well as with a direct intervention in labor markets to keep wage demands commensurate with productivity gains. Over the business cycle, our approach provides a foundation for counter-cyclical measures aimed simultaneously at encouraging investment and protecting employment during downturns. 


\section{References}

[1] Caballero, Ricardo J., and Mohamad L. Hammour, "The Cleansing Effect of Recessions," American Economic Review, 1994, 84, pp. 1350-1368.

[2] —. "On the Timing and Efficiency of Creative Destruction." Quarterly Journal of Economics, forthcoming, 1996a.

[3] —. "On the Ills of Adjustment." Journal of Development Economics, forthcoming, 1996b.

[4] —. "Appropriability and the Business Cycle." Work in progress, 1996c.

[5] —. "The Macroeconomics of Specificity." Work in progress, 1996d.

[6] Grout, Paul A. "Investment and Wages in the Absence of Binding Contracts: A Nash Bargaining Approach." Econometrica, March 1984, 52(2), pp. 449-460.

[7] Hall, Robert E., and Edward P. Lazear. "The Excess Sensitivity of Layoffs and Quits to Demand," Journal of Labor Economics, 1984, 2(2), pp. 233-257.

[8] Klein, Benjamin, Robert G. Crawford, and Armen A. Alchian. "Vertical Integration, Appropriable Rents, and the Competitive Contracting Process." Journal of Law and Economics, October 1978, 21(2), pp. 297-326.

[9] Myerson, Roger B., and Mark A. Satterthwaite. "Efficient Mechanisms for Bilateral Trading," Journal of Economic Theory, 1983, 28, pp. 265-281.

[10] Williamson, Oliver E. "Transaction-Cost Economics: The Governance of Contractual Relations." Journal of Law and Economics, October 1979, 22 (2), pp. 233-261. 